\title{
Combination Therapy with Granulocyte Colony-Stimulating Factor, All-Trans Retinoic Acid, and Low-Dose Cytotoxic Drugs for Acute Myelogenous Leukemia
}

\author{
Kensuke Usuki, Koichi Kitazume, Mitsue Endo, Keiko Ito, Seiko Iki and Akio Urabe
}

\begin{abstract}
A 67-year-old man presented with acute myelogenous leukemia (M2). Peripheral blood examination revealed a leukocyte count of $1,700 / \mu$ l with $1 \%$ myeloblasts, and bone marrow aspiration showed $\mathbf{4 2 . 6 \%}$ myeloblasts with Auer bodies. Culture of his marrow cells at diagnosis showed that granulocyte colony-stimulating factor (G-CSF) promoted cell proliferation, while alltrans retinoic acid (ATRA) inhibited the proliferative effect of G-CSF and induced differentiation. Combination therapy with G-CSF, ATRA, and low-dose cytotoxic drugs achieved complete remission without severe marrow suppression.
\end{abstract}

(Internal Medicine 34: 1186-1189, 1995)

Key words: differentiation, low-dose cytosine arabinoside therapy, cytarabine ocfosfate

\section{Introduction}

Low-dose cytosine arabinoside ( $\mathrm{araC}$ ) is widely used for myelodysplastic syndrome and in elderly patients with acute myelogenous leukemia (AML) $(1,2)$. It was originally reported as a differentiation therapy but it frequently induces myelosuppression due to its cytotoxic effects (3). All-trans retinoic acid (ATRA) appears to be the most effective agent for promoting the differentiation of acute promyelocytic leukemia, a subtype of AML (4). We present a case of AML (M2) in which treatment with a combination of ATRA, granulocyte-colony stimulating factor (G-CSF), cytarabin ocfosfate (a prodrug of araC) $(5,6)$, and low-dose cyclophosphamide achieved complete remission without severe marrow suppression.

\section{Case Report}

A 67-year-old man was admitted to our hospital with fever on March 22, 1993. Peripheral blood examination revealed that the leukocyte count was $1,700 / \mu 1$ with $1 \%$ atypical myeloblasts and $56.5 \%$ mature granulocytes. In addition, the hemoglobin was $8.6 \mathrm{~g} / \mathrm{dl}$, the platelet count was $15.4 \times 10^{4} / \mu \mathrm{l}$, the level of fibrin/fibrinogen degradation products (FDP) was $84 \mu \mathrm{g} / \mathrm{dl}$, the thrombin-antithrombin complex level was $39.0 \mathrm{ng} / \mathrm{ml}$, and the $\alpha 2$ plasmin inhibitor-plasmin complex level was $4.8 \mu \mathrm{g} / \mathrm{ml}$. Bone marrow aspiration showed slightly hypocellular marrow and $42.6 \%$ myeloblasts with Auer bodies. Chromosomal analysis of the marrow cells disclosed a karyotype of $56, \mathrm{XY},+\mathrm{X},+\mathrm{X}$, $+1,+2, \operatorname{del}(5)(\mathrm{q} 13, \mathrm{q} 33),+8,+10,+11,+14,+20,+22$. These findings led to the diagnosis of M2 AML according to the FAB classification (7) associated with disseminated intravascular coagulation (DIC). $\left[{ }^{3} \mathrm{H}\right]$ thymidine incorporation assay of cultured marrow cells obtained at diagnosis showed that G-CSF promoted cell growth and that ATRA inhibited this effect of GCSF (Fig. 1). Morphological examination of cells in liquid culture revealed that ATRA induced modest differentiation and that G-CSF did not block this differentiating effect of ATRA (Table 1). He had suffered from pneumoconiosis since 1981, and blood gas analysis revealed a $\mathrm{pH}$ of 7.41 , a $\mathrm{PaO}_{2}$ of 61.5 $\mathrm{mmHg}, \mathrm{a} \mathrm{PaCO}$ of $60.4 \mathrm{mmHg}$, and an $\mathrm{O}_{2}$ saturation of $91.4 \%$.

Because of his chronic respiratory failure and the in vitro data, we administered ATRA (Tretinoin ${ }^{\circledR}$, provided by NIH, Bethesda, MD, USA; $45 \mathrm{mg} / \mathrm{m}^{2}=70 \mathrm{mg}$ daily) and cytarabine ocfosfate (SPAC; a prodrug of cytosine arabinoside; $50 \mathrm{mg}$ daily/ Starasid ${ }^{\circledR}$, Nippon Kayaku, Tokyo, Japan) together with heparin after obtaining informed consent. Within 2 weeks, his DIC was well controlled by heparin therapy and FDP became undetectable. After administration of ATRA and SPAC for 36 days, marrow leukemic blasts decreased to $19.2 \%$, but the peripheral blood leukocyte count decreased to $1,500 / \mu 1$ with a decline of mature granulocytes (15\%). The results of the above in vitro studies plus the onset of sepsis and neutropenia prompted 


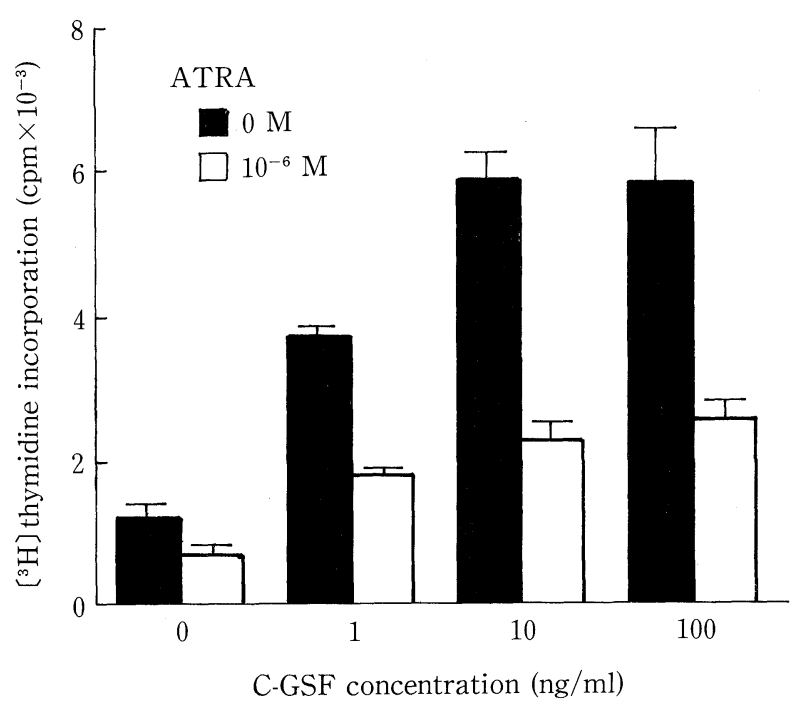

Figure 1. Effect of all-trans retinoic acid and granulocyte colony-stimulating factor on the growth of bone marrow cells cultured from the patient at the time of initial diagnosis. White columns and black columns indicate $\left[{ }^{3} \mathrm{H}\right]$ thymidine incorporation (cpm) in the presence of the indicated concentrations of granulocyte colony-stimulating factor with and without $10^{-6} \mathrm{M}$ retinoic acid, respectively. Bars indicate the $\mathrm{SD}$ of triplicate experiments. The assay was done according to the method of Tsuchiya et al (22). us to start subcutaneous administration of G-CSF (Filgrastim, Kirin, Tokyo, Japan) at a daily dose of $75 \mu \mathrm{g}$ in combination with ATRA and SPAC. Within 4 days, the peripheral leukocyte count increased to $2,700 / \mu \mathrm{l}$ with an increase of mature granulocytes (44\%). After administration of G-CSF, ATRA, and SPAC for 36 days, leukemic blast cells decreased to $4.6 \%$

Table 1. Effect of all-trans retinoic acid and granulocyte colony-stimulating factor on differentiation of the patient's bone marrow cells in liquid culture. The assay was done as described by Motoji et al (21). Briefly, cells were collected by sternal aspiration at the time of initial diagnosis and subjected to liquid culture. After 4 days of incubation with the indicated concentrations of granulocyte colony-stimulating factor and retinoic acid, the cells were examined.

\begin{tabular}{cccc}
\hline $\begin{array}{c}\text { G-CSF } \\
(\mathrm{ng} / \mathrm{ml})\end{array}$ & $\begin{array}{c}\text { ATRA } \\
(\mathrm{M})\end{array}$ & $\begin{array}{c}\text { Immature blasts } \\
(\%)\end{array}$ & $\begin{array}{c}\text { Mature granulocytes } \\
(\%)\end{array}$ \\
\hline 0 & 0 & $73.5 \pm 2.1$ & $24.7 \pm 2.1$ \\
0 & $10^{-6}$ & $67.3 \pm 3.2$ & $32.7 \pm 3.2$ \\
10 & 0 & $70.3 \pm 4.0$ & $29.7 \pm 4.0$ \\
10 & $10^{-6}$ & $67.3 \pm 2.5$ & $32.7 \pm 2.5$ \\
\hline
\end{tabular}

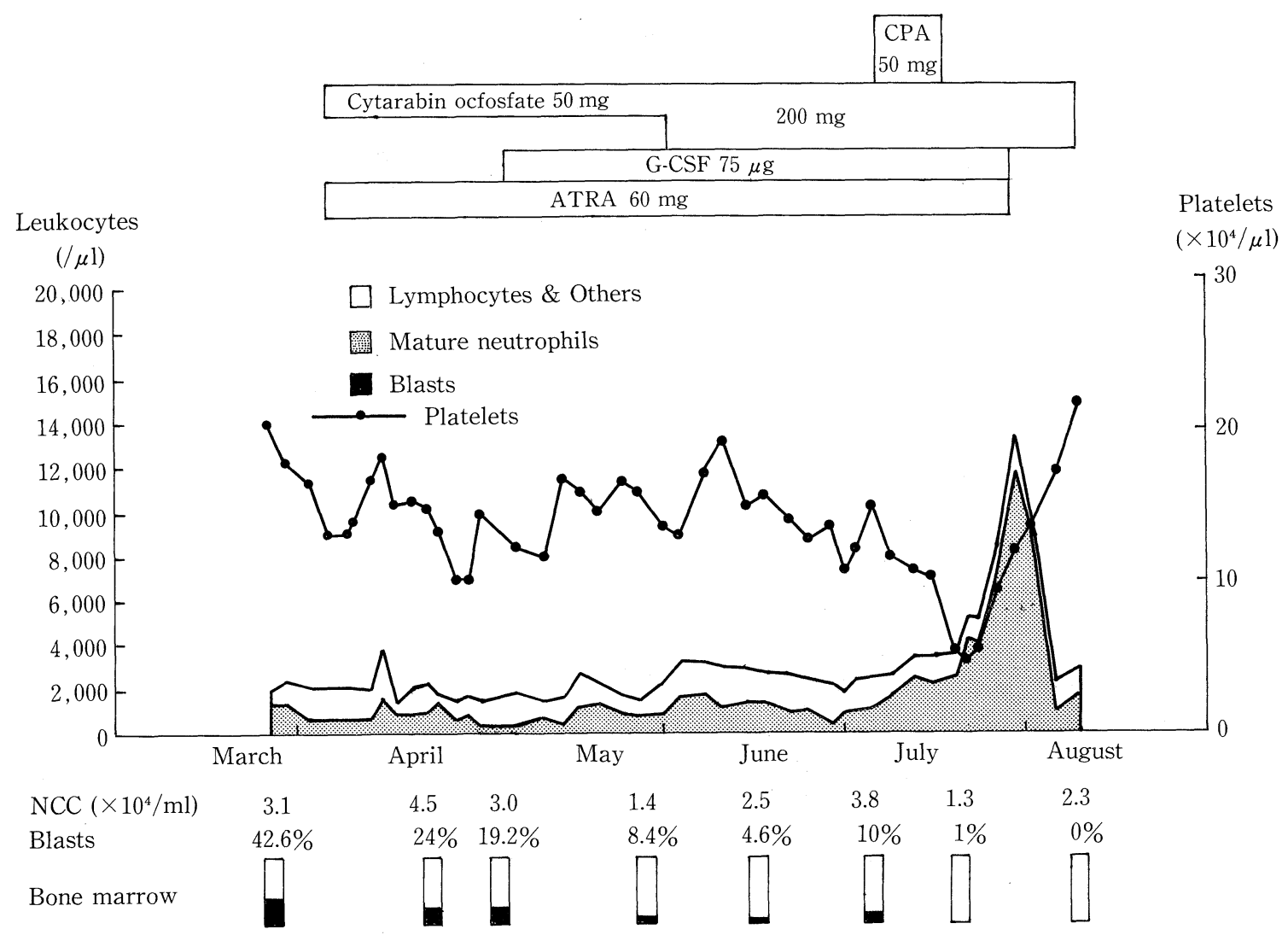

Figure 2. Clinical course of the patient.

CPA: cyclophosphamide, NCC: nucleated cell counts. 


\section{UsuKI et al}

in the bone marrow. Hemoglobin concentration also gradually decreased to $7.5 \mathrm{~g} / \mathrm{dl}$. However, following administration of a higher dose of SPAC (200 mg daily) with G-CSF and ATRA for 18 days, marrow blasts increased to $10 \%$, therefore we added oral cyclophosphamide at $50 \mathrm{mg}$ daily. Following administration of cyclophosphamide in combination with ATRA, G-CSF, and SPAC for 14 days, marrow blasts decreased to $1 \%$. On day 122 of treatment, peripheral blood and bone marrow examination showed complete remission.

\section{Discussion}

In the present case, combined administration of ATRA and SPAC $(50 \mathrm{mg} /$ day $)$ produced a favorable response. SPAC $(1-\beta-$ D-arabinofuranosylcytosine 5'-stearylphosphate) is a prodrug of cytosine arabinoside, and its oral administration at a daily dose of $100-300 \mathrm{mg}$ is reported to give an equivalent plasma araC concentration to that achieved with low-dose araC (10 mg/ $\mathrm{m}^{2}$ twice daily) $(5,6)$, which is a cytotoxic chemotherapy but is also known as a differentiation therapy for AML (2). Since lowdose araC has a cytotoxic effect and sometimes induces severe myelosuppression (3), very-low-dose araC therapy $\left(3 \mathrm{mg} / \mathrm{m}^{2}\right.$ twice daily) has also been developed $(8,9)$. It has been shown to be as effective as a low-dose regimen (10), despite a peak plasma araC concentration at least 10 -fold lower than in the other regimen (11). Thus, the administration of SPAC at $50 \mathrm{mg} /$ day may correspond to very-low-dose araC therapy. ATRA is the most effective agent for producing the differentiation of acute promyelocytic leukemia (4). Brief exposure to ATRA is reported to increase the in vitro araC sensitivity of cells from two established AML cell lines (12), and therapy with low-dose araC plus ATRA is reported to induce severe myelosuppression (13), as also occurred in the present case.

G-CSF usually promotes the growth of AML cells in vitro (14). The combination of G-CSF or GM-CSF with chemotherapy has been reported to induce severe myelosuppression or leukemic regrowth (15-18). On the other hand, it was reported that G-CSF enhances the in vitro differentiation of AML cells in the presence of ATRA (19) and that ATRA inhibits the GCSF-induced proliferation of hemopoietic progenitor cells (20). In the present case, ATRA inhibited the promotion of the growth of immature blasts by G-CSF, although this cytokine did not inhibit the in vitro slight differentiation effect of ATRA. Moreover, the addition of G-CSF to the patient's therapy ameliorated the marrow suppression induced by the combination of ATRA and SPAC without obvious leukemic regrowth, and helped to achieve a good response. Following the subsequent addition of low-dose cyclophosphamide, complete remission was achieved without severe myelosuppression. These findings suggest the possibility that in the present case the combined administration of G-CSF and ATRA enhanced the differentiation effect of SPAC which was equivalent to very low-dose araC therapy (2) or the alternative possibility that ATRA played a role in the augmentation of antileukemic activity by SPAC and inhibition of leukemic regrowth promoted by G-CSF which stimulated granulopoiesis. Further investigation is needed to clarify the most suitable schedule for the combined administration of ATRA, low dose araC, G-CSF, and other cytotoxic drugs in AML.

\section{References}

1) Wisch JS, Griffin JD, Kufe DW. Response of preleukemic syndromes to continuous infusion of low-dose cytarabine. N Engl J Med 309: 1599, 1983.

2) Housset M, Daniel MT, Degos L. Small doses of ARA-C in the treatment of acute myeloid leukaemia: differentiation of myeloid leukaemia cells? Br J Haematol 51: 125, 1982.

3) Mufti GJ, Oscier DG, Hamblin TJ, Bell AJ. Low doses of cytarabine in the treatment of myelodysplastic syndrome and acute myeloid leukemia. N Engl J Med 309: 1653, 1983.

4) Huang ME, Ye YC, Chen SR, et al. Use of all-trans retinoic acid in the treatment of acute promyelocytic leukemia. Blood 72: 567, 1988.

5) Ohno R, Tatsumi N, Hirano M, et al. Treatment of myelodysplastic syndromes with orally administered $1-\beta$-d-arabinofuranosylcytosine-5'stearylphosphate. Oncology 48: 451, 1991.

6) Ueda $T$, Kamiya $K$, Urasaki $Y$, et al. Clinical pharmacology of 1- $\beta$-darabinofuranosylcytosine-5'-stearylphosphate, an orally administered long-acting derivative of low-dose 1- $\beta$-d-arabinofuranosylcytosine. Cancer Res 54: 109, 1994.

7) Bennet JM, Catovsky D, Daniel M-T, et al. Proposed revised criteria for the classification of acute myeloid leukemia. Ann Intern Med 103: 620 1985.

8) Wosley A, Mufti GJ, Copplestone JA, et al. Very-low-dose cytarabine for myelodysplastic syndromes and acute myeloid leukaemia in the elderly. Lancet i: 966, 1986.

9) Pesce A, Cassuto JP, Bayle J, et al. Very-low-dose cytarabine for elderly patients. Lancet i: 1436, 1986.

10) Chromienne C, Najean $Y$, Degos $L$, et al. Present results of the treatment of myelodysplastic syndromes with low-dose cytosine arabinoside. Acta Haematol 78 suppl (1): 109, 1987.

11) Poirier $\mathrm{O}$, Chromienne $\mathrm{C}$, Castaigne $\mathrm{S}$, et al. Pharmacokinetic data on very-low-dose cytarabine. Lancet i: 1436, 1986.

12) Lishner M, Curtis JE, Minkin S, McCulloch EA. Interaction between retinoic acid and cytosine arabinoside affecting the blast cells of acute myeloid leukemia. Leukemia 3: 784, 1989.

13) Venditti A, Stasi R, Masi M, et al. All-trans retinoic acid plus low doses of cytarabine for the treatment of "poor-risk" acute myeloid leukemias. Ann Hematol 66: 59, 1993.

14) Vellenga E, Young DC, Wagner K, et al. The effects of GM-CSF and GCSF in promoting the growth of clonogenic cells in acute myeloblastic leukemia. Blood 69: 1771, 1987.

15) Estey $\mathrm{E}$, Thall PF, Kantarjian $\mathrm{H}$, et al. Treatment of newly diagnosed acute myelogenous leukemia with granulocyte-macrophage colony-stimulating factor (GM-CSF) before and during continuous-infusion high-dose ara-C+daunorubicin: comparison to patients treated without GM-CSF. Blood 79: 2246, 1992.

16) Ohno R, Naoe T, Kanamaru A, et al. A double-blind controlled study of granulocyte colony-stimulating factor started two days before induction chemotherapy in refractory acute myeloid leukemia. Blood 83: 2086, 1994

17) Estey $E$, Thall $P$, Andreeff $M$, et al. Use of granulocyte colony-stimulating factor before, during, and after fludarabine plus cytarabine induction therapy of newly diagnosed acute myelogenous leukemia or myelodysplastic syndromes: comparison with fludarabine plus cytarabine without granulocyte colony-stimulating factor. J Clin Oncol 12: 671, 1994

18) Goto $\mathrm{H}$, Shimazaki $\mathrm{C}$, Ashihara E, et al. Recombinant human granulocyte colony-stimulating factor in combination with continuous infusion of cytosine arabinoside for the treatment of refractory acute myelogenous leukemia. Acta Haematol 89: 144, 1993.

19) Colombat PH, Santini V, Delwel R, et al. Primary human acute myelob- 


\section{G-CSF, ATRA, and Cytotoxic Drugs for AML}

lastic leukemia: an analysis of in vitro granulocytic maturation following stimulation with retinoic acid and G-CSF. Br J Haematol 79: 382, 1991.

20) Smeland EB, Rusten L, Jacobsen SEW, et al. All-trans retinoic acid directly inhibits granulocyte colony-stimulating factor-induced proliferation of CD34 ${ }^{+}$human hematopoietic progenitor cells. Blood 84: 2940, 1994.

21) Motoji T, Takanashi M, Fuchimoue M, et al. Effect of recombinant GM-
CSF and recombinant G-CSF on colony formation of blast progenitors in acute myeloblastic leukemia. Exp Hematol 17: 56, 1989.

22) Tsuchiya $\mathrm{H}$, Adachi $\mathrm{N}$, Aou $\mathrm{N}$, et al. Responses to granulocyte colonystimulating factor (G-CSF) and granulocyte-macrophage CSF in $\mathrm{Ph}^{1}$ positive acute lymphoblastic leukemia with myeloid surface markers. Blood 77: 411, 1991. 